\author{
Military Technical College \\ Kobry Elkobbah, Cairo, \\ Egypt.
}

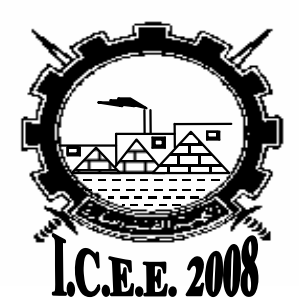

$4^{\text {th }}$ International Conference On Chemical \& Environmental Engineering 27-29 May 2008

\title{
PROTECTION AGAINST BIOLOGICAL WEAPONS
}

\author{
HAMED ROSHDY EL-KADY*
}

\begin{abstract}
Weapons of mass destruction are characterized by enormous ability to kill large number of human subjects whearas their destructive effects can be extended for a long time duration after their applications.

Weapons destruction can be categorized into: Nuclear, Chemical, and Biological weapons.

The biological weapons of mass destruction are frequently refered to as those weapons available to poor countries which do not possess the funding and technicalities required for fabrication of other sorts of weapons.

The biological weapons of mass destruction can categorized into: Germ weapons Ethnic weapons - and destructive genetically modified organisms.

The germ weapons are oriented to cause infection by dangerous diseases or to cause toxication by total poison. The natural characteristics of the germ as immunity and sensitivity can be altered through induced mutations.

The ethenic weapons are developed through the production of mixrobial organisms genetically modified in view of acquiring the ability to infect certain human species who carry a specified genetic constituation but not the others.

Means of protection of hyman race and his environment against deterious effect of weapons of mass destruction are receiving increasing interest worldwide. It is anticipated that more emphases will be given to protective measures against potential hazard of weapons of mass destruction in order to assure safety for mankind existence nowadays and in the future.
\end{abstract}

\footnotetext{
* Former Chairman Atomic Energy Authority
} 